\title{
Integrated Community-Based Disaster Management Program in Taiwan: A Case Study of Shang-An Village
}

\author{
LIANG-CHUN CHEN ${ }^{1, \star}$, YI-CHUNG LIU $^{2}$ and KUEI-CHI CHAN ${ }^{2}$ \\ ${ }^{1}$ Graduate Institute of Building and Planning, National Taiwan University, Taipei City 106, \\ Taiwan, ROC; ${ }^{2}$ National Science \& Technology Center for Disaster Reduction (NCDR), 6F., \\ No. 200, Sec. 3, Sinhai Rd., Da-an District, Taipei City 106, Taiwan, ROC
}

\begin{abstract}
Taiwan has long made efforts to increase community emergency response capability, due to its vulnerability to earthquakes, typhoons, landslides and debris flows. Not until recent major natural disasters, such as the 1999 Chi-Chi Earthquake, Typhoon Toraji and Typhoon Nari, has the government reformed its policy toward empowering the community to take actions in hazard mitigation, emergency preparedness and emergency response. A new initiatve, Integrated Community-Based Disaster Management Program (ICBDM), was launched in 2001 by the Executive Yuan to achieve the goal of strengthening community resistance. The paper, taking Shang-An Village as an example, describes Taiwan's new community-based disaster management program. Through a participatory process, community residents have learned how to analyze vulnerable conditions, discover problems, develop solutions and establish an organization to implement disaster management tasks. Further, basic response training courses and a disaster scenario were held in order to improve their emergency response capability. Based on the case study, a phased process, including initiation, assessment, planning and practice, is generalized.
\end{abstract}

Key words: community-based disaster management, empowerment, participatory process, resistance

\section{Introduction}

Taiwan's specific location at the juncture of Pacific, Eurasian, and Philippine Sea plates is subject to frequent earthquakes. Some earthquakes have caused major damage, such as the 1999 Chi-Chi Earthquake, which led to 2,455 deaths and 11,305 injured. Taiwan is also vulnerable to typhoons because it is located in the path of west Pacific typhoons. Roughly 3 or 4 typhoons strike Taiwan each year. Due to the global warming effect, recent typhoons produced a huge amount of rain in a short time and had resulted in great floods over the past few years. For

^ Author for correspondence: E-mail: lcchen@ccms.ntu.edu.tw 
example, the 2001 Nali Typhoon brought serious flood damage and massive financial losses. In addition, debris flow has emerged as a threatening hazard because of the huge ground shaking of the Chi-Chi Earthquake as well as the heavy rainfall. For instance, the debris flows following the 2001 Typhoon Toraji caused heavy casualties across the country. The devastation from the extensive natural hazards has shown the importance of emergency responses capability. However, the governments' emergency services might be delayed or affected because of the type or size of a disaster and the geographical features of the area affected. Under these kinds of conditions, communities, therefore, play a significant role in responding to the early stages of a catastrophic disaster. From past catastrophic disaster events, community involvement has shown great efficiency in emergency response and disaster recovery. As a result, we can predict that the community-based disaster management will be the best approach for governments' efforts to help citizens' preparedness for future disasters and will become an important issue for Taiwan's disaster management.

This paper will first review different community-based disaster management programs in Taiwan. The second section will explain the concept of the Integrated Community-Based Disaster Management program (ICBDM), and will explore its process and procedures through the case study of Shang-An Village. Then, we will address the problems, which emerged while implementing the project. The final section will cover recommendations for implementing the program in the future.

\section{Community-based Disaster Management Approaches}

The term, community-based disaster management, has risen in the late twentieth century. In fact, local governments have used citizen participation for disaster response since half a century ago. Over the past few years, the community-based disaster management concept has been promoted nationwide with different programs. These programs can be simply categorized into three types.

1. Type A: disaster prevention and response groups sponsored by fire fighting agencies.

Citizens volunteering as firefighters, due to a shortage of professionals, goes back to World War II. The trend for fire fighting agencies to recruit volunteers for emergency response tasks has gradually been accepted and a few voluntary groups have been organized by the National Fire Agency (NFA). For example, volunteer firefighters became official in 1998 in order to assist in fire suppression and rescue (Taipei County Fire Department, no date). The Phoenix Teams were developed in 1999 to provide emergency medical assistance. The Female Fire Safety Publicity Teams aimed at fire 
prevention were also created in 1999 (Taipei County Fire Department, no date). It is important to know that individuals can apply to participate in the above three voluntary groups as long as they complete required training.

After the Chi-Chi Earthquake, the NFA started to emphasize community preparedness and response capabilities with the creation of the Neighborhood Rescue Teams (NRTs) in 2000 (Taipei County Fire Department, no date). Different from other voluntary groups sponsored by the NFA, the NRTs are formed by members of a neighborhood who want to be better prepared for the hazards that threaten their communities. The goal of the NRTs is to prepare communities to take care of themselves in the aftermath of a major disaster when first responders who provide emergency services are not able to provide immediate assistance. As such, The NRTs are applicable to various disasters.

2. Type B: disaster response and recovery actions actively undertaken by communities

A couple of years ago, some residents of communities started to help each other after catastrophic disasters, when the emergency personnel could not provide immediate assistance. For example, the residents of Feng-Qiu Village, Nantou County warned the people who lived in the downstream area immediately before the debris flow happened and then assisted in victim removal as well as relief distribution after the $1996 \mathrm{Ty}-$ phoon Herb. Chang-Cing community, Taipei County has also actively organized its residents to neighborhood patrols, disaster prevention and preparedness, and emergency response efforts since 1998 (Wei, 2001). In Long-An village and $\mathrm{Wu}-$ Gong community of Nantou County, the residents' involvement in the first response and post-disaster recovery after the Chi-Chi Earthquake not only reduced life and property losses but also helped communities to rebound rapidly from disaster effects (Wei, 2001).

There are similarities in the above communities. One is that the residents actively formed as groups to assist their neighborhoods immediately in the aftermath of major disasters. Second, these communities never have had governmental sponsorship for emergency response training before. Third, the residents of these communities have regularly participated in community activities so that the close relationship contributed to their interdependence after disaster events.

3. Type C: community-based disaster management programs

After the extensive earthquakes, floods, and debris flows that have occurred throughout Taiwan over the past few years, academia started to promote the community-based disaster management concept. Several academic groups, referring to Japan's reconstruction experience after the great Hashin-Awaji Earthquake and FEMA's Project Impact, began promoting national use of the concept. The National Science \& Technology Centre of 
Disaster Reduction (NCDR), in conjunction with the graduate institute of building and planning at National Taiwan University (NTU), first developed a community-based disaster management program in 1999 (Chen et al., 2001). Two communities, Ming-Shing and Shing-Jia located in Taipei City were selected as case studies. The program provided the communities opportunities for assessing their vulnerability, discovering problems and developing solutions by involving public sectors, experts and community residents. The Soil \& Water Conservation Bureau (SWCB) has also retained slope failure prevention experts to develop emergency evacuation routes for debris flow and has sponsored disaster debris flow disaster prevention practices since 2001 (SWCB, no date). Further, both governments and citizens have recognized the need for enhancing community preparedness and response capabilities for future hazards after the 2001 Typhoon Toraji and Typhoon Nali. In support of the awareness, the Executive Yuan launched an initiative called Integrated Community-Based Disaster Management (ICBDM) at the end of 2001 (National Disasters Prevention \& Protection Commission, 2002). This initiative focused on promoting pre-disaster planning, facilitating disaster resistance capability, and supporting communities with a framework to move toward a more resilient and sustainable future. The goal of the initiative was to bring communities together to take actions that prepare for and protect themselves against natural disasters in a collaborative effort. Ten hazardous communities stricken by the Chi-Chi Earthquake, and Typhoon Toraji and Typhoon Nari were chosen as pilot communities to show the benefits of communities working together in a systematic way to reduce vulnerability, enhance resistance, and promote resilience. In terms of the program activities, the characteristics of previous three programs are quite different (see Table I).

\section{The Case of Shang-An Village}

Shang-An Village, Shili Township, Nantou County, became a pilot community for the ICBDM in 2001. The overall objective of the project was to encourage Shang-An toward a goal of becoming a disaster resistant, resilient and sustainable community. To accomplish the objective, a phased process, which included initiation, assessment, planning and practice, was developed.

\subsection{SHANG-AN BACKGROUND}

Shang-An is a pretty agricultural village located in central Taiwan, $37 \mathrm{~km}$ from the urban center of Nantou County. This village is rather small with a total land area of $7.6 \mathrm{~km}^{2}$. According to the Shili Household Registration Office in October 2003, the population was 1,506 and the occupation of most inhabitants was farming. The community's location and topography 
Table I. Three types of community-based disaster management programs in Taiwan

\begin{tabular}{|c|c|c|c|}
\hline & Type A & Type B & Type C \\
\hline Period & 1960-present & 1996-present & 1999-present \\
\hline Initiator & $\begin{array}{l}\text { Fire fighting } \\
\text { agencies }\end{array}$ & $\begin{array}{l}\text { Community } \\
\text { leaders }\end{array}$ & $\begin{array}{l}\text { Academia, natural hazard } \\
\text { professionals \& communities }\end{array}$ \\
\hline $\begin{array}{l}\text { Targeted } \\
\text { hazard types }\end{array}$ & Fire & $\begin{array}{l}\text { Earthquake } \\
\& \text { landslide }\end{array}$ & Earthquake, flood \& debris flow \\
\hline $\begin{array}{l}\text { Targeted } \\
\text { audiences }\end{array}$ & $\begin{array}{l}\text { Individual } \\
\text { volunteers }\end{array}$ & $\begin{array}{l}\text { Community leaders } \\
\& \text { enthusiastic persons }\end{array}$ & $\begin{array}{l}\text { Leaders, group members \& } \\
\text { residents in communities }\end{array}$ \\
\hline Highlights & $\begin{array}{l}\text { Emergency } \\
\text { response }\end{array}$ & $\begin{array}{l}\text { Emergency response } \\
\& \text { post-disaster recovery }\end{array}$ & $\begin{array}{l}\text { Mitigation, preparedness, and } \\
\text { emergency response }\end{array}$ \\
\hline $\begin{array}{l}\text { Program } \\
\text { approaches }\end{array}$ & $\begin{array}{l}\text { Basic response } \\
\text { skills training }\end{array}$ & None & $\begin{array}{l}\text { Community participatory } \\
\text { workshop, basic response skills } \\
\text { training, and disaster scenario }\end{array}$ \\
\hline
\end{tabular}

(i.e. along the Jyun-da Mountain Range, Chen-You-Lan River and ChenYou-Lan fault) is directly responsible for many of the risks associated with natural disasters. These geological features have contributed landslides, debris flows, floods and earthquakes. For instance, the Chi-Chi Earthquake, Typhoon Herb and Typhoon Toraji caused extensive property damage and significant casualties to the community (Figure 1).

\subsection{PROJECT PARTNERS}

The first step of the Shang-An ICBDM project was to build community partnerships. Project partners included community leaders, experts in various hazard mitigation fields (e.g. flood, landslide, and public policy), local emergency management agencies (e.g. the fire brigade and the public health center of Shili Township), local governments (e.g. Nantou County and Shili Township governments), public institutions (e.g. the SWCB and the 921 Earthquake Post-disaster Recovery Commission ${ }^{1}$ ), and academia (e.g. the NCDR and NTU). Project partners contributed a wide range of assistance in accordance with each contributor's specialty or responsibility. In short, the Shang-An project partnerships consisted of experts, public agencies, and a planning team that was composed of community group leaders and professionals from NCDR and NTU.

\subsection{PROJECT IMPLEMENTATION}

Paton and Johnston (2001) describe community empowerment strategies based on community participation, which can facilitate problem

\footnotetext{
1 The name 921 Earthquake reflects its occurence on 21 September 1999.
} 
identification, solution development and strategies implementation. They suggest hazard scenarios can also be used to elicit hazard perceptions, and the information and resources for implementing mitigation strategies. To implement the project, three units were developed by the planning team. A participatory process was first undertaken in order to encourage public involvement in hazard mitigation planning. The second unit was basic responding skills training and the third unit was a practical disaster scenario exercise. The second and third units were both used to improve the community's emergency response capability. In general, each activity of every unit was delivered in a 2-hour section, one evening each other week over a 5-month period.

\subsubsection{Participatory Process}

By the participatory process, participants would learn how to analyze vulnerable conditions, find ways to solve problems, develop strategies for risk reduction, and establish an organization to implement disaster management tasks. It was anticipated to obtain views and ideas from the community residents about disaster experiences, hazard problems, and potential solutions through an informal, flexible and relaxing atmosphere. The process was divided into 6 steps, which are:

Step 1 - Orientation: The goal of the orientation was to involve the public in the project. The orientation addressed the objectives of the project, how to implement it and what are the expected results. It was expected that if the residents clearly understood the importance of the project and what they could gain from involvement, it would be easier to recruit potential participants. After confirming interested residents, participants broke into smaller groups in accordance with the neighborhood where they lived in order to go deep into discussion and focus on more specific issues in the following steps.

Step 2 -Collecting disaster experiences: Information about past disaster events could be collected from disaster experiences. Step 2 was designed to reveal disaster history of the community and acknowledge descriptions of emergency conditions by reviewing past disaster events and personal experiences. Through exchanging information, participants could understand information about the natural hazards in their community (e.g., frequency of occurrence, areas likely to be affected most, magnitude and intensity, spatial extent, duration, seasonal pattern and existing warning system). These past disaster experiences could also be used to help participants with identifying the hazards which threaten their community and supporting further discussion in the following steps. From the past disaster experiences collection, the most threatening hazards for Shang-An were typhoons, debris flows, and flooding. The following steps then would concentrate on these hazards. 
Step 3 - Assessing vulnerabilities: Assessing vulnerability involved identifying risk areas, exploring problems, and putting these areas on a map. First, by conducting a field survey, the participants could handle more detailed problems via direct observation of community environment with hazard experts. These experts, with different specialties, such as geologists, hydrologists and slopeland experts, could help them with examining the community's risks for natural hazards and identifying its vulnerabilities to those risks. Second, the participants had to highlight on a detail map the areas of past disaster locations, their effects, and potential hazardous areas discovered from the field survey. Mapping the boundaries of natural hazard areas and pinpointing the locations of vulnerable buildings or facilities could help guide participants to identify where they should be most concerned.

Step 4 - Evaluating problems and developing solutions: This step addressed problems evaluation, solutions development and mitigation strategies classification. First, the participants develop a list of problems based on the findings from the above steps. According to the list, the participants started to discuss specific details about the community's people, services, specific facilities and structures that are most at risk and then brainstormed how to solve these problems or lessen their impacts. For ease of discussion, the participants had to group these solutions into three categories, family, community and government, in terms of their respective capabilities or responsibilities. It was important that community identified its own strategies using its own reasons and mitigation goals.

Step 5 - Establishing a community-based disaster management organization: Once the participants had defined the community's response strategies, they could then develop a framework for a community-based hazard mitigation organization. A well-defined organizational structure could be either a new form or a combination of existing community groups. It was important to stress that the framework of the organization is flexible, so that it could be changed to fit the needs of different circumstances (Figure 2).

Step 6 - Final presentation: The final step in this process was to share project results with other community inhabitants. It was important to commend each person for attending the course by distributing a certificate of completion to each participant. In addition, it was the best way to inform the community about the benefits of hazard mitigation and the effects it would have on the community in the future so that they also would be willing to input mitigation efforts. Local officers and emergency management personnel were also invited to the presentation in order to help the community seek support from the administrative side. 


\subsubsection{Training}

The purpose of this training is to provide the members of the community-based disaster management organization with the basic skills that they will need to respond to their community's immediate needs in the aftermath of a major disaster, when emergency services are not immediately available. After discussing with participants and understanding their needs, the planning team set up courses targeted at first-aid, search \& rescue, and walkie-talkie operations. Trained emergency personnel, including local firefighters and emergency medical service personnel, taught the courses. The courses consisted of 12 hours of training and emphasized hands-on practice.

\subsubsection{Disaster scenario exercise}

As a last unit, the participants were required to apply the skills and knowledge learned throughout the preceding units to a simulated disaster exercise. The intent of the exercise was to give the participants a practical perspective on overall organization operations, while further improving their skills.

\section{Discussion}

The Shang-An ICBDM project was not only to move the community toward protecting their lives and properties, but also to empower the community to take actions in minimizing their risk of loss, and encourage the ability of the community to continue to improve their quality of life. In short, the project is about enabling the community to be aware of hazard mitigation, to strengthen their capability to resist natural disasters, and to develop an organization in order to carry out sustainable risk reduction actions. Through a phased process, participants of Shang-An ICBDM project worked together to identify potential hazards, assess the risks from these hazards, discover problems and develop strategies. Additionally, the participants have established a community database about current rescue equipments, refuge facilities and a list of vulnerable people through comprehensive surveys. To commend their remarkable accomplishments, the 921 Earthquake Post-disaster Recovery Commission also provided a grant to Shang-An Community-Based Disaster Management Organization to purchase necessary rescue equipments.

In spite of the remarkable achievement, we still faced a number of obstacles while implementing the project. These problems are briefly described below: 
1. The weakness/decline of public awareness of natural hazards, and measures that can be undertaken to increase disaster preparedness and promote mitigation.

Based on the experience of Shang-An ICBDM project, we have found that residents who have been directly damaged by natural disasters were more active in participating in the project and contributed to more specific discussion throughout the activities. Other residents who did not have injuries or losses were less willing in attending the activities. Also, it was difficult to involve them in group discussion.

In fact, only a minority of residents participated in the project. The low attendance resulted from many factors. First, the people who experienced major disasters were usually in a bad economic condition. As a result, they would like to spend their time and efforts on making money rather than participating in community activities. Especially, the project seemed cannot change their economic situation in a short time. Second, people were more interested in structural projects, such as housing retrofits \& embankment building, and less concerned about hazard mitigation education programs and nonstructural risk reduction measures. In addition to the above reasons, the public awareness of hazard mitigation and disaster preparedness seemed to decrease after a span (Chen et al., 2002) so that it was difficult to keep current volunteers interested and involved in the ICBDM program. The fact that they have little interest in hazard mitigation between disasters may result from considerations to economic development, real estate. In addition, problems like crime and education seem to absorb more attention than hazard mitigation (Prater and Lindell, 2000).

2. The insufficiency of community-based disaster management professionals, guidelines and materials.

Recently, government at all levels has focused on community-based disaster management efforts. However, it is just in an initial phase to implement the concept of community-based disaster management. The obstacles for governments to promote the program nation wide are due to the lack of project guidelines, educational materials, and technical assistance personnel.

3. The lack of sustained support from government makes the communitybased disaster management concept hard to put into action.

The provision of information on the hazard risk and education in proper mitigation measures will result in public awareness and behavior (Sims and Baumann, 1983). Recently, some public sectors have taken account of community-based disaster management and have embarked on some pilot projects. However, the lack of legislation, funding and implementing mechanisms will result in difficulties when developing follow up actions and activities. 


\section{Recommendations}

Every community is different and the hazards they may face are different also. For example, conducting a community-based disaster management project in a rural village is far different from working with a metropolitan community due to the diversities of population, density, demographic and geographic characteristics. Strictly speaking, the program should be revised when targeted at different communities in order to function efficiently. However, it will be impossible to tell precisely what should be done in every situation. We therefore generalize an applicable process and potential project partners from the Shang-An experience. The following information is developed to help communities in implementing a community-based disaster management project.

\section{Utilize a phased process}

The Shang-An ICBDM project was implemented through a process of project orientation, vulnerability assessment, hazard problems discovery, disaster management strategies development, organization establishment, emergency response skills practice and disaster scenario exercise. Such a process could be organized into four phases: initiation, assessment, planning, and practice (Figure 3). The first phase is meant to orient the project through assessing community resources, organizing a planning team, building partnerships, and involving the public. At this point, the planning team should identify and recruit potential participants. Based on the Shang-An experience, we may conclude that potential participants are community group leaders, NRT, the Neighborhood Lookout Team (NLT), and the residents who are interested in the project. Studies addressing household adjustment to seismic hazard also found correlations of demographic characteristics with seismic adjustments (Lindell and Perry, 2000; Lindell and Prater, 2000). These demographic characteristics may be guidance on potential participants as well. In the next phase, participants are expected to perform a vulnerability assessment through disaster experience discussion, field survey, problem exploring, and hazard mapping. Past disaster experiences play a key point at this stage. In fact, participants not only identify the threatening hazards to their community but also learn from the past trough reviewing disaster experiences. A number of studies have shown that disaster experience is related to risk perception, hazard intrusiveness and hazard adjustment adoption (Lindell and Perry, 2000; Lindell and Prater, 2000; Weinstein, 1989; Sah and Chen, 2003; Chen et al., 2002). Phase three is about discovering problems, developing solutions, classifying strategies according to the proper respondents (i.e. household, community and government), and establishing a community-based disaster management organization. By a systematic planning process, participants will clearly 
understand what their community can do in regard to hazard mitigation, emergency preparedness and emergency response. In addition, the establishment of the organization would help the community with enforcing disaster management strategies as well as assisting in saving lives and protecting property in the event of a major disaster. Consequently, basic responding skills training courses and a disaster scenario may be arranged in the last phase in order to improve community capability of responding to and coping with the aftermath of a disaster.

2. Include different types of public and private organizations as project partners

The success of the Shang-An ICBDM project relied on a well-developed community partnership. In addition to the traditional participants from central, county, and township governments, different players with wider and more diverse backgrounds were recruited in order to implement the project efficiently. The partnerships of this project were composed of public agencies, experts, and a planning team. The collaboration of the project partners assisted with money, knowledge and technical support. The experience may contribute to building the ICBDM partnerships in future projects. Figure 4 presents a recommended model for community-based disaster management programs. There are three main categories of project partnership; public agencies, experts and a planning team respectively. Public agencies offer financial and administrative support. Experts provide knowledge and suggestions in hazard mitigation as well as emergency response. The planning team consists of two groups; one is the

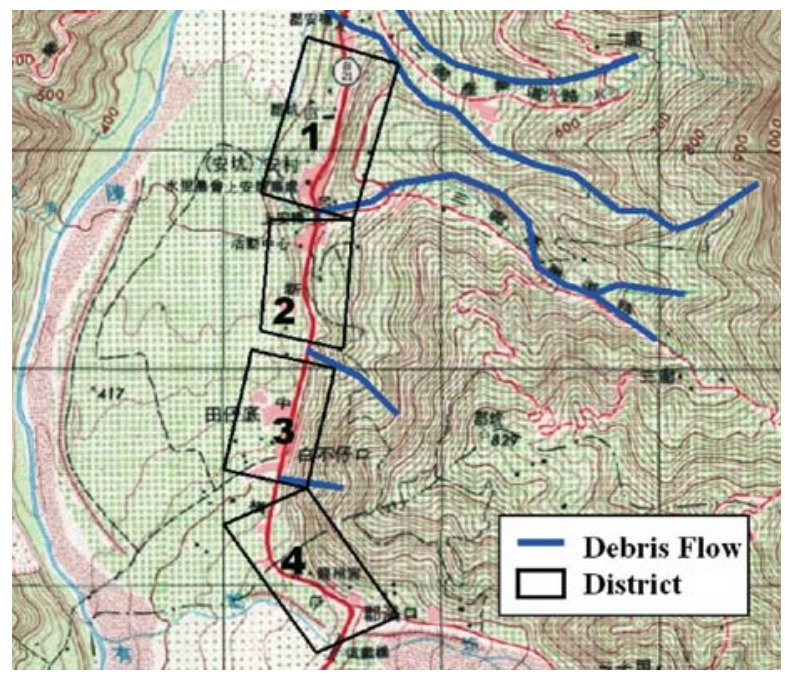

Figure 1. Shang-An map. 


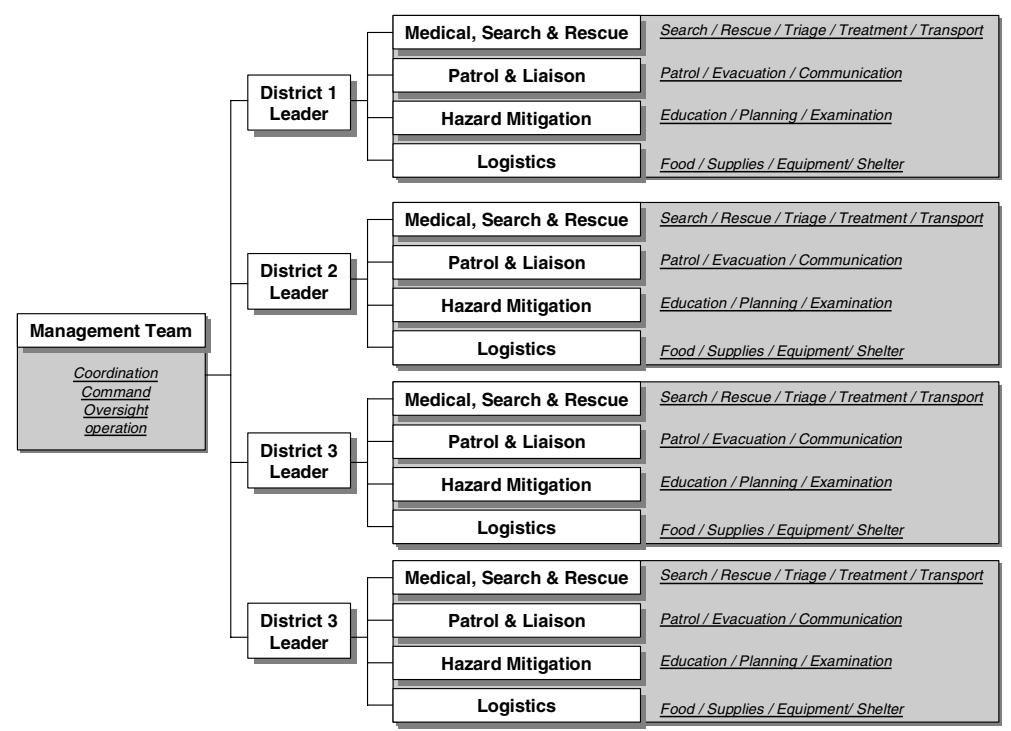

Figure 2. Shang-An ICBDM organization.

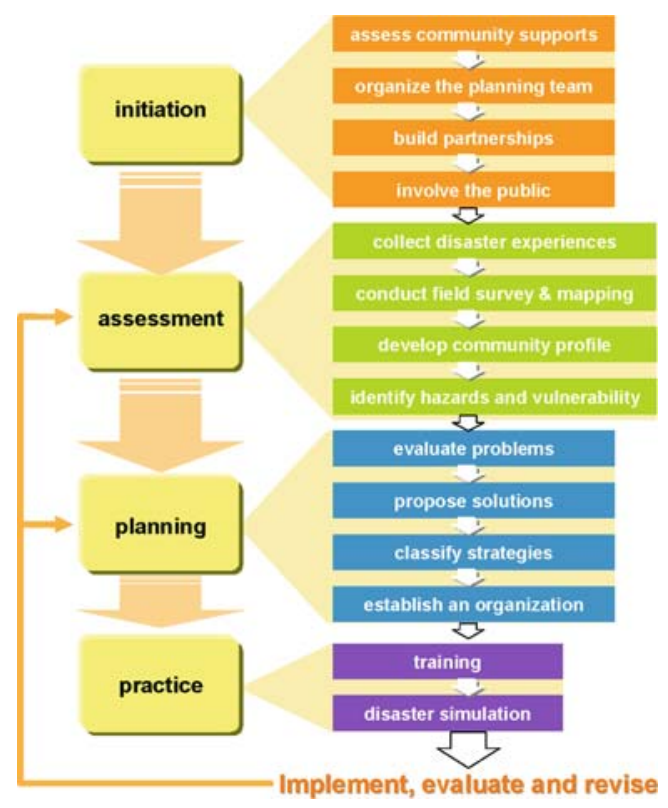

Figure 3. Phased approach of ICBDM project.

community-working group; another was the advisory team, whose main role is as a facilitator for project implementation. The community-working group responds for setting up a project timeline, determined locations of activities, considered project directions and encouraged participation was 


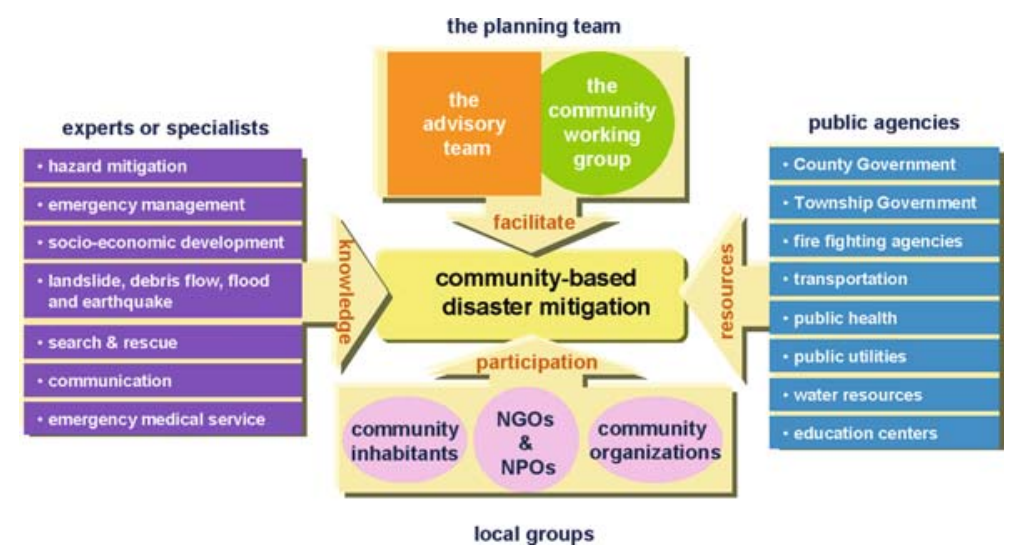

Figure 4. Potential partners of ICBDM project.

composed of community group leaders. On the other hand, the advisory team provides ideas and guidance for project structure, monitors progress of the project, offers detailed information about each step, gives technical assistance when necessary, coordinates communication between community and other partners, and mobilizes resources needed to implement the project. It is the most important that the community itself acts as the key element of the project.

\section{Conclusion}

Typhoons, earthquakes and other natural hazards may cause severe damage to the environment and create catastrophic economic and social impacts. Certainly, natural hazards will always threaten the built environment. Thus, the need for community-based disaster management is neverending. The following section provides suggestions for community-based disaster management in the future.

From the case study of Shang-An ICBDM Project, we found that it is important to provide regular education on natural hazards, and steps that can be taken before, during, and after a disaster event as well as follow up training in order to raise or maintain public awareness, skills and knowledge. The suggestion is consistent with recommendations from other studies, which have found repetition is important for enhancing hazard awareness and eliciting protective action (Fitzpatrick and Mileti, 1991; Lindell and Prater, 2000; Lindell and Perry, 2004). The development of specific educational materials targeted at different community characteristics is also necessary.

As mentioned earlier, it will be an obstacle to implement the program on a large scale since the lack of professionals. The central government 
agencies have also noticed that the advisory team is critical for implementing the program national wide. Therefore, the national experts from NCDR and SWCB have been working on training county level teams to advise the hazardous villages since 2004. Moreover, it may be considerable to combine disaster management program with community development plan in order to keep public interest in hazard mitigation. Look for opportunities to incorporate disaster management concepts and community empowerment into sustainable development. In summary, a sustainable mechanism for implementing community-based disaster management program and a long-term personnel training plan on both professional and community sides are needed in order to achieve a meaningful level of hazard mitigation throughout the entire country. In addition, sustained administrative and financial supports from local governments are also essential for sustainable community-based disaster management efforts.

In order to plan and to build safer communities, we need to understand our communities and their vulnerability to natural hazards. The community-based disaster management program offers a series of practical steps, by combining the various approaches of hazard identification and vulnerability assessment, problems discovery and solutions development, basic response skills practice and disaster scnario exercise, as well as public awareness and education to assist communities to reduce vulnerability to natural hazards and to effectively respond to emergency situations. Through the community-based disaster management program, individuals and communities not only can protect themselves and their property from the risk of natural hazards instead of relying on external support, but also, can create a better place to live, protect the natural environment, improve resistance to disasters, improve business opportunities, manage growth, and preserve the community's history, culture, and other attributes for future residents.

Only the residents of a community know what value they place on different aspects of their community. And no one but a community can really ensure that those values endure. The community-based disaster management will show communities how communities that carry out community-based disaster management thoughtfully can become safer, more disaster resistant, and more resilient, with stronger economies and a higher quality of life.

\section{References}

Chen, L. C., Liu, Y. C., and Chan, K. C.: 2002, The Relation of Hazard Experience and Community Education to Household Hazard Perception, National Science \& Technology Center for Disaster Reduction, Taipei, Taiwan (in Chinese). 
Chen, L. C., Wang, J. J., and Liu, Y. C.: 2001, A Comparative Study of Community Hazards Awareness and Learning of Hazard Mitigation, National Science \& Technology Center for Disaster Reduction, Taipei, Taiwan (in Chinese).

Fitzpatrick, C. D. and Mileti, D. S.: 1991, Motivating public evacuation, Int. J. Mass Emerg. Disasters 9, 137-152.

Lindell, M. K. and Perry, R. W.: 2000, Household adjustment to earthquake hazard: A review of research, Environ. Behav. 32, 590-630.

Lindell, M. K. and Perry, R. W.: 2004, Communicating Environmental Risk in Multiethnic Communities, Sage, Thousand Oaks, CA.

Lindell, M. K. and Prater, C. S.: 2000, Household adoption of seismic hazard adjustments: A comparison of residents in two states, Int J. Mass Emerg. Disasters 18, 317-338.

National Disasters Prevention \& Protection Commission (2002), Disaster prevention \& Relief Plans: Integrated Community-based Disaster Management. National Disasters Prevention \& Protection Commission. Taipei, Taiwan: Available at: http://www.ndppc.nat.gov.tw/ ndppc.htm (in Chinese).

Paton, D. and Johnston, D.: 2001, Disasters and communities: Vulnerability, resilience and preparedness, Disaster Prev. Manage. 10, 270-277.

Prater, C. S. and Lindell, M. K.: 2000, Politics of hazard mitigation, Nat Hazards Rev. 1, 7382.

Sah, J. P. and Chen, C. W.: 2003, The influence of flood hazard on choosing adjustment measure for household: Citing area His-Chih as an example. 2003 National Land Management and Development Conference Proceedings, 2-281-2-289 (in Chinese).

Sims, J. H. and Baumann, D. D.: 1983, Educational programs and human response to natural hazards, Environ. Behav. 15, 165-189.

Taipei County Fire Department: no date, Application of Civil Volunteers. Taipei, Taiwan: Taipei County Fire Department. Available at: http://www.tpf.gov.tw/index-ok.htm (in Chinese).

The Soil and Water Conservation Bureau: no date, Taipei, Taiwan: The Soil and Water Conservation Bureau. Available at: http://www.swcb.gov.tw/ (in Chinese).

Wei, Y. L.: 2001, A study of effective factors in building local disaster resistant communities in Taiwan. Master's thesis. National Taiwan University (in Chinese).

Weinstein, N.: 1989, Effect of personal experience on self-protective behavior, Psychol. Bull. 105, 31-50. 